\section{All about axolotls}

\author{
An interview with Laura Muzinic, MSc, Associate Director of the \\ Ambystoma Genetic Stock Center
}

The Ambystoma Genetic Stock Center (AGSC) at the University of Kentucky is a self-sustaining breeding colony of the Mexican axolotl (Ambystoma mexicanum), an odd-looking aquatic salamander with a remarkable capacity for healing. Associate Director Laura Muzinic oversees the shipping process and gives researchers and educators the information they need in order to care for animals and embryos. Muzinic tells Lab Animal about her work at the AGSC and how she became involved with the axolotl.

\section{Tell us about the AGSC.}

Since 1969, the National Science Foundation has continuously funded the AGSC, formerly known as the Indiana University Axolotl Colony. This collection of axolotl salamanders has become the largest self-sustaining population in the world. The AGSC staff maintains an average breeding population of 1,000-1,200 adults, as well as a highly variable number of hatchlings, juveniles and non-breeding adults. The lab staff obtains spawn regularly throughout most of the year and sends weekly shipments of embryos, larvae, adults and supplies to researchers and educators worldwide. On average, the AGSC staff ships about 400 eggs each week to different institutions throughout the United States, although this number fluctuates during the course of the academic year.

\section{Why are axolotls so important?}

The axolotl is a salamander with an amazing capacity for healing and regeneration. Unlike mammals, the axolotl's wound-healing mechanism usually does not involve the formation of scar tissue. Instead, tissues adjacent to an amputated limb will revert to an 'embryonic stem cell-like' state and regrow the missing tissue. Laboratories at universities worldwide are working independently and in collaboration on projects investigating the details of the mechanisms by which this process occurs. The key to the axolotl's ability to regenerate will perhaps one day be its most important gift to medical science.

\section{The AGSC supplies axolotls to $\mathrm{K}-12$ teachers, as well as to labs. How are axolotls used in a classroom setting?}

Axolotl embryos measure approximately 2-3 $\mathrm{mm}$ in diameter. Because of their large size, a dissecting microscope easily reveals cleavage furrows, allowing researchers or students to observe the transitions between each stage of development. Because the embryos are sturdy and large in size, it is possible for a growing number of educators to use the axolotl to give their students some 'hands-on' experience with the scientific method.

\section{How would you describe your job?}

As the Associate Director of the AGSC, I am the first person with whom researchers and educators come into contact when they request axolotls. I receive all orders placed and make plans for when axolotl adults should be bred in order to fulfill our embryo orders. I also arrange all shipping details for domestic and international orders. I answer questions from educators or hobbyists about housing and caring for their axolotls, and I help them when diseases or other health issues arise.

\section{How did you get involved in this work?}

I have always been interested in working with aquatic animals. As an undergraduate at Heidelberg College in Tiffin, $\mathrm{OH}$, my senior research project was on the diets of forage fish in Lake Erie. As a graduate

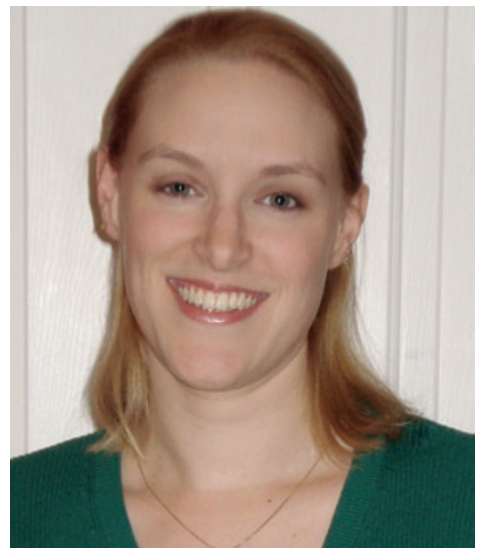

student at Kentucky State University in Frankfort, KY, my research focused on red claw crayfish and hybrid striped bass. After I received my Master's Degree in Aquaculture, I was in search of a profession that would allow me to continue to work with some sort of aquatic animal. Dr. Randal Voss, Director of the AGSC, contacted me about this position. He was looking for a candidate with an aquaculture background, because axolotls are pedomorphic, which means that most of them live out their entire life cycle in the aquatic form they had as juveniles. Many amphibians begin their lives by hatching from eggs as aquatic larvae and then undergo metamorphosis, a restructuring of the anatomy and physiology to modify their bodies to suit life on land. But not all salamanders mature into land-dwelling animals, and axolotls are one example.

\section{What advice would you give to someone} interested in a similar job?

I would suggest that they have a love for science and aquatic animals. I would suggest that they obtain at least a Bachelor's Degree to enhance their basic knowledge about such creatures. I would advise anyone interested to also research and work with several types of aquatic species to make sure it is something that truly interests them.

\section{ACKNOWLEDGMENTS}

All the work done by the AGSC is possible because of the generous support of the National Science

Foundation (current award number NSF-DBI-0443496). 